\title{
USE OF ENZYME LINKED IMMUNOSERBENT ASSAY (ELISA) FOR THE DIAGNOSIS OF CLINICALLY SUSPECTED REFERRED HUMAN CYSTIC AND ALVEOLAR HYDATIDOSIS CASES IN NEPAL
}

\begin{abstract}
Joshi D D*, Joshi H*, Chand P B
\section{ABSTRACT}

The objective of the study is to diagnose suspected human cystic and alveolar hydatidosis cases in Nepal. In this present study diagnosis of active clinical cases of cystic and alveolar hydatidosis referred to our centre by different hospitals, nursing homes and private clinics of Kathmandu were carried out from August 1999 to March 2001 by using ELISA. Among 44 samples including 31 samples from male and 13 samples from female. $35(79.54 \%)$ were found positive. Regarding the age group maximum 13 samples were collected within 6-15 years age of which $12(27.3 \%$ ) were found serrologically positive. Ultrasonogram (USG) and computerised tomography (CT scan) are the method of choice to image the hepatic and other abdominal cysts. In this study $75 \%$ of CT scan suspected cases were found positive by ELISA. Hence these imaging techniques must be used to detect the shape, size and location of the cyst but not as confirmative. Blood examination results, biochemical tests and stool and urine examination have basically no relation with hydatidosis.
\end{abstract}

Key Words: Cystic, alveolar hydatidosis, ELISA, genotype, strain.

\section{INTRODUCTION}

Cystic and alveolar hydatidosis is caused by the larval form of cestode parasite Echinococcus granulosus belonging to family taeniidae. Immunological investigation is a basic complement to clinical and instrumental diagnosis of this parasitic disease. Serodiagnosis is carried out by tests such as double diffusion, immunoelectrophoresis (IEP), indirect hemagglutination (IHA) and ELISA which identify antibodies against crude antigen. ${ }^{1}$ Development of imaging techniques in medical science, world health organization article of May-June 1995 issue provides an overview of today's' modern technology in radiation medicine. Imagine techniques have got the diagnostic potentiality to image the morphological features of hydatid cysts located in the lungs or in the liver. In cystic echinococcosis, liver is the most frequently involved organ, $\mathrm{x}$ ray, ultrasound and computerised tomography are the widely applied imagine techniques. ${ }^{2}$

Cystic hydatidosis are usually unilocular and may vary in size from only a few cms to $>30 \mathrm{cms}$ containing many litres of fluid. Clinical symptoms and pathology of these chronic larval cestode infection is usually related to site, size and condition of cysts and especially pressure effects of the space occupying versions. Occasionally rupture of E. granulosus cysts may participate acute anaphylaxis. ${ }^{3}$

Variety of Immunological tests have been used to detect IgG, $\operatorname{IgA}, \operatorname{IgM}$ and $\operatorname{IgE}$ antibody responses in patients with cystic hydatid disease. The ELISA test provides a sensitive initial

* National Zoonoses \& Food Hygiene Research Centre (NZFHRC), Kathmandu, Nepal.

Address for correspondence : $\quad$ Dr. D. D. Joshi

National Zoonoses \& Food Hygiene Research Centre (NZFHRC)

Chagal, Kathmandu, Nepal.

Email: ddjoshi@healthnet.org.np 
screening technique which requires low quantities of antigen and sera. IgG is the dominant class of specific antibody in cystic hydatidosis. Enzyme immunoassay employ antibodies or antigens conjugated to enzymes in such a way that the Immunological and enzymatic activity of each moiety is maintained. ${ }^{3}$ The prevalence, incidence and risk factors of infection by E. granulosus were studied in the domestic and street dogs of Kathmandu, Nepal using an ELISA coproantigen test and the prevalence was $5.7 \%(5 / 88 \mathrm{dogs})$ in the city and $1.8 \%(3 / 171 \mathrm{dog})$ in the veterinary clinics. ${ }^{4}$

Clinical diagnosis of hydatidosis may be difficult and rely on detection of space occupying masses primarily with x-ray, ultrasound or CT scans, although images may also be difficult to interpret. Larval cestodes are among the few parasitic infections where the basis for laboratory diagnosis is primarily serology, surgery still remain basic form of treatment. In this study ELISA was used for the diagnosis of human cystic and alveolar hydatidosis in Nepal. Cross reactivity between echinococcosis and cysticercosis (Taenia solium infection) has been identified. ${ }^{5}$

\section{MATERIALS AND METHODS}

All the serum samples were collected from the suspected patients referred by different hospitals, nursing homes and private clinics.

The basic principles of the ELISA is detection of antibody using enzyme - labelled antiglobulin. The antigen is coupled to a solid phase support and the sera thought to contain antibody are incubated in this sensitized carrier. Excess serum components are washed away and then the enzyme - labelled antiglobulin (conjugate) is added. The conjugate will become attached to the antigen-antibody complexes on the carrier surface and the amount of conjugate attached is measured by the amount of substrate that it degrades. ${ }^{6}$

For diagnosis of hydatidosis commercially available Echinococcus serology screening test, microwell ELISA cit. EG-8. 48 test was used. Number of microwells needed (Three for controls plus number of samples) were break off and placed in the strip holder $100 \mu$ l of negative control to well \# 1,100 $\mu 1$ of weak positive control to well \# 2,100 $\mu$ l of strong positive control to well \# 3, and $100 \mu$ l of diluted (1:128) test samples to the remaining well were added and incubated at room temp $\left(15^{0}\right.$ to $\left.25^{\circ} \mathrm{C}\right)$ for 10 minutes, which was washed 3 times with diluted wash buffer then added two drops of enzyme conjugate to each well and incubated at room temperature for 5 minutes. The contents was shacked out and again washed 3 times with wash buffer and followed by distilled water. In each well 1 drop of substrate A and 1 drop of substrate B was added, mixed well by tapping string holder and incubated for 5 minutes then two drops of stop solution was added.

The reading obtained from ELISA plate reader with $450 \mathrm{~nm}$ filters. It was considered that 0.0 to 0.49 OD units indicated Negative, 0.5 to 1.19 OD unit indicated weak positive and 1.2 and above OD unit indicated strong positive as given in the manual.

\section{RESULTS}

In the present study diagnosis and monitoring of active clinical cases of Alveolar and cystic hydatidosis disease referred to our centre by different hospitals and private nursing homes were carried out. Early diagnosis by ELISA and imaging techniques of active cases was done and they were monitored and sent to the hospital for surgery as well as chemotherapy. Forty -four serum samples from suspected active hydatid cases as well as suspected neurocyticercosis cases were received from August 1999 to March 2001 from the hospitals, nursing homes and private clinics. There were $35(79.54 \%)$ found positive and nine specimens testing negative. During this period 31 samples were collected from males and 13 samples were from females.

Out of 44 total sample tested thirty one serum samples screened from male, $23(74.19 \%)$ were found positive, which is $52.5 \%$ from total sample screened. In females out of 13 sample screened $12(92.20 \%)$ serum samples were diagnosed positive, which is $27.3 \%$ out of 44 samples. Regarding the age group maximum 13 samples including 10 male and 3 female of 6-15

Table I : Age and Sexwise ELISA Test result

\begin{tabular}{l|c|c|c|c|c|cc|c|c}
\hline \multirow{2}{*}{ Age } & \multicolumn{4}{|c|}{ Male } & \multicolumn{3}{c}{ Female } & \multicolumn{3}{c}{ Total } \\
\cline { 2 - 11 } & $\begin{array}{c}\text { Total } \\
\text { tested }\end{array}$ & $\begin{array}{c}\text { Total } \\
\text { positive }\end{array}$ & $\mathbf{\%}$ & $\begin{array}{c}\text { Total } \\
\text { tested }\end{array}$ & $\begin{array}{c}\text { Total } \\
\text { positive }\end{array}$ & $\mathbf{\%}$ & $\begin{array}{c}\text { Total } \\
\text { cases }\end{array}$ & $\begin{array}{c}\text { Total } \\
\text { positive }\end{array}$ & $\%$ \\
\hline $0-5$ & 1 & 1 & 3.2 & 0 & 0 & - & 1 & 1 & 2.3 \\
\hline $6-15$ & 10 & 9 & 29.0 & 3 & 3 & 23.1 & 13 & 12 & 27.3 \\
\hline $16-25$ & 6 & 4 & 12.9 & 2 & 2 & 15.4 & 8 & 6 & 13.6 \\
\hline $26-35$ & 8 & 6 & 19.4 & 2 & 2 & 15.4 & 10 & 8 & 18.2 \\
\hline $36-45$ & 4 & 2 & 6.5 & 2 & 2 & 15.4 & 6 & 4 & 9.1 \\
\hline 45 above & 2 & 1 & 3.2 & 4 & 3 & 23.1 & 6 & 4 & 9.1 \\
\hline Total & $\mathbf{3 1}$ & $\mathbf{2 3}$ & $\mathbf{5 2 . 3}$ & $\mathbf{1 3}$ & $\mathbf{1 2}$ & $\mathbf{2 7 . 3}$ & $\mathbf{4 4}$ & $\mathbf{3 5}$ & $\mathbf{7 9 . 5 4}$ \\
\hline
\end{tabular}


Table II : Blood examination results of suspected patients for cystic and alveolar hydatidosis

\begin{tabular}{l|cc|c|c}
\hline \multicolumn{1}{c}{ Tests } & Total patients & Normal range & \multicolumn{2}{c}{ Abnormal } \\
\cline { 3 - 5 } & & & High range & Low \\
\hline Total Count & 10 & $9(5100-12700)$ & $1(28,700)$ & - \\
\hline Neutrophyl & 10 & $9(42-78)$ & $1(90)$ & - \\
Lymphocyte & 10 & $9(20-45)$ & - & $1(7)$ \\
\hline Esinophyls & 10 & $7(1-6)$ & $3(8-12)$ & - \\
\hline Monocyte & 6 & $6(1-4)$ & - & - \\
\hline Hemoglobin & 8 & $7(10.8-17.2)$ & - & $1(9.6)$ \\
\hline ESR & 7 & $5(2-10)$ & $2(32.39)$ & - \\
\hline
\end{tabular}

Table III : Comparison of various scanning with ELISA

\begin{tabular}{l|c|c|c}
\hline \multicolumn{1}{c|}{ Scanning } & No. of patients & Suspected & ELISA positive Result \\
\hline CT Scan & 8 & 8 & 6 \\
\hline X-ray & 1 & 1 & 1 \\
\hline USG & 3 & 3 & 3 \\
\hline MRI & 1 & 1 & 1 \\
\hline
\end{tabular}

Table IV : Biochemical examination of suspected patients for cysticercosis/hydatidosis

\begin{tabular}{l|c|c|c}
\hline & Total tested & Normal range & $\begin{array}{c}\text { ELISA } \\
\text { Positive Result }\end{array}$ \\
\hline Urea & 4 & $(9.2-36.1)$ & 3 \\
\hline Cretenine & 4 & $(0.7-08 \mathrm{mg} \%)$ & 4 \\
\hline Bilirubin total & 3 & $(0.7-1 \mathrm{mg} \%)$ & 3 \\
\hline Bilirubin conjugate & 3 & $(0.3-\mathrm{mg} \%)$ & 3 \\
\hline SGPT & 3 & $(15.6 \mu \mathrm{l}-24.7)$ & 3 \\
\hline SGOT & 2 & $(17.2 \mu \mathrm{l}-24.8)$ & 2 \\
\hline Alkaline Phosphatage & 1 & $139.0 \mu \mathrm{l}$ & 1 \\
\hline Sugar & 3 & $(86-95 \mathrm{mg} \%)$ & 2 \\
\hline Sodium & 1 & 138 & 1 \\
\hline Potassium & 1 & 3.5 & 1 \\
\hline
\end{tabular}

years age received during the study period, the maximum positive rate i. e. (12) $27.3 \%$ was observed. In this serological diagnostic study, one sample received from the age group 0-5 years of male which in testing gave positive result. See detail in Table I.

\section{Blood examination results of suspected patients for cystic} and alveolar hydatidosis: Out of 44 patients referred for ELISA test, only 10 patients had requested for blood examination before this test. One patient found high range of total count and neutrophyl and 3 patients had high range of esinophyls counts and 2 patients had high range of ESR, similarly one had low range of lymphocyte one had low range of hemoglobin. Rest of all posses normal range of blood parameters. The result revealed that in both alveolar and cystic hydatidosis as well as suspected neurocysticercosis cases no remarkable relation observed with blood examination (Table II).

Comparison of various imaging techniques with ELISA: Out of 44 patients referred 8 of them had performed CT-scan in which 6 of CT scan suspected cases were found positive for ELISA also, while three of them had performed USG, X-ray and MRI by each, which were found positive for ELISA test. During inspection the hydatidosis suspected cases scanning usually performed were CT-scan, X-ray, MRI and USG and other imaging techniques which were comparatively necessary technique as the imaginary purpose (see table III).

Biochemical analysis of blood of suspected patients usually carried out, Urea, Bilirubin, SGPT, SGOT, Alkaline phosphate, sugar and sodium/potassium level in blood. Only maximum 4 patients had performed this test. Among them all the suspected patients posses in normal range the result indicated that there is absolutely no relation with the biochemical components.

Stool and Urine examination results: Very few patients were referred for stool/urine test before ELISA. Patients who had performed urine test revealed that in one patient - Albumin trace, 3 of them pus cells (1-8), 2 of them calcium oxalate (1012), 1 of them amorphous urate and 5 of them had epithelial 
cells (1-2). In stool one of them posses ova of T. trichiuris, 2 of them were infected with Giardia and Entamoeba histolytic cyst and one of them was infected with $\mathrm{H}$. nana the result revealed that there is no relationship with stool and urine examination with hydatidosis.

\section{DISCUSSION}

Present study revealed that out of 44 samples 35 (79.54\%) were positive by ELISA test which included 23/31 (74.19\%) male and 12/13 (92.30\%) female positive cases, Which are $52.3 \%$ male and $27.3 \%$ female among total 44 cases. 6-15 years age group patients were found maximum positive rate than other age groups. While similar study carried out from National Zoonoses and Food Hygiene Research Centre from March to December 1995, out of 32 blood samples 22 were found positive. Among positive cases, 12 (55\%) were male and $10(35 \%)$ were female. The age group 35 and older had the highest number of positive $15(68 \%))^{7}$ The comparison of the previous results with the present indicates that maximum number of clinically suspected cases were also positive by confirmative ELISA test. Since the clinical features appeared very lately and few persons can afford for expensive diagnostic techniques most of the cases remain still hidden in the communities.

Dog fecal samples were tested for E. granulosus by coproantigen ELISA test and 154 (3.8\%) dogs were found positive. ${ }^{8}$ One of the study carried out on hydatidosis in water buffaloes of western part of Kathmandu revealed that out of 535 water buffaloes examined $21 \%$ were found positive, of which $11 \%$ lung, $6 \%$ liver and $4 \%$ both liver and lungs. ${ }^{9}$ In human out of 23 sera samples clinically suspected hydatidosis $17(74 \%)$ were found positive in ELISA test. ${ }^{8}$ Imagine techniques have got the diagnostic potentiality to image the morphological features of the hydatid cysts located in the lungs or in the liver. Cysts in the lungs can be detected by x-ray examination. Ultrasonogram (USG) and computerized topography (CT scan) are the methods of choice for the diagnosis of hepatic and other abdominal cysts. In this study 75\% of CT-scan suspected cases were found positive by ELISA. The image and ultrasound signs that correlates with each type of cyst will be described in the oral exposition. The different ultrasound images shown in the ecographic test, allow us to establish the different biological stages of the cyst, and the complication it may suffer as well as its evolution and growth. A good morphological and tomographical ultrasound diagnosis allows us to prescribe the suitable and appropriate surgical or medical treatment or both at a time or pair of the cystic hydatidosis. ${ }^{10}$ Hence these imaging techniques must be used to detect the shape, size and location of the cyst but not as confirmative. ELISA tests the confirmative test for cystic and alveolar hydatidosis since it also close cross-reaction with cysticercosis.

Out of 44 sample quite a number of patients were clinically suspects as a case of neurocysticercosis, however this ELISA test gives $8-10 \%$ cross reaction results with cysticercosis patients. One of the study on differential serodiagnosis for cystic and alveolar echinococcosis using fractions of Echinococcus granulosus cyst fluid (Antigen B) and E. multilocularis protoscolex (EM18) revealed that preliminary blind tests for differentiation of $\mathrm{AE}$ from other diseases were carried out by Em18-immunoblot analysis using crude antigens of protoscoleces of E. multilocularis. Approximately 83\% (35 of 42) of the sera from patients with $\mathrm{AE}$ sera were from inactive cases with calcified lesions. All other sera, including neurocysticercosis ( 0 of 8$)$, trematodiases ( 0 of 5 ), or nematodiases ( 0 of 5$)$, were negative. This serological result should not be used as an aid in diagnosis of hydatidosis and should not be interpreted as diagnostic for cysticercosis by itself. $^{11}$

Hydatidosis is common in those places where there is close association between man-sheep-dog, man-pig-dog or manbuffalo-dog. The sheep strain predominates in most domestic hosts and human through out the Europe. ${ }^{12}$ But we identified three E. granulosus genotypes (G1, G5 and G6) in the mammalias host from Kathmandu. Three distinct COI and NDI sequences were identified anomgst the 25 isolates following alignment with the published E. granulosus G1 G9 Genotypic sequences. Eighteen samples, including fourteen buffaloes isolates, two sheep isolates and two goat isolates, produced identical COI and NDI sequences to the cattle strain (G5 genotype, whereas one buffalo isolate, two sheep isolates and two goat isolates, shared identical sequences with those of the common sheep strain (G1 genotype). Notably, the two human isolates examined produced identified COI and NDI sequences to the G6 (camel strain) genotype; neither were infected with the G1 or G5 genotype, the latter being the predominant strain (18/25 isolates examined) identified in the study.

Blood examination results Biochemical tests and stool and urine examination have basically no relation with hydatidosis although in some cases total count, neutrophyl, lymphocyte esinophyls counts were high and low, that might be due to other causes. In case of the cysticercosis, stool examination is very much essential because of its auto infection possibility but in hydatidosis cases sometimes protoscoleses may be observed in sputum test in case the cysts are rapture in lungs. 


\section{ACKNOWLEDGMENT}

This study was supported by International Development Research Centre (IDRC) Canada. The authors are grateful to IDRC particularly Mr. Andres Sanchez, Programme Officer, and Dr. Peter Schantz from Centre for Disease Control Division (CDC) Atlanta Georgia for their technical support. Last but not least, I would like to thank to all NZFHRC staff.

\section{REFERENCES}

1. Siracusano, A. Notarigiacomo, S, Loppolo, S. Franchi C, Rigano. R. Immunodiagnosis of E. glanulosus infection in Italy. Archirvos intemationalionales De La Hidatidosis volume xxxi : Lisboa Portugal. 1997; 222.

2 Joshi, D. D. Schantz, P. M. Craig, P. S. Diagnosis of cystic Echinococcosis/Hydatidosis in Humans by clinical, imagine techniques and serology. Archivos internationales De La Hydatidosis volume xxxii : Lisboa - Portugal. 1997; 225.

3. Report on Sero Diagnosis of cystic Hydatid Diseases. National Zoonoses and Food Hygiene Research Centre, Tahachal, Kathmandu. 1993; 1-8.

4. Baronet, D. , haltner-Toews, D. Craig, P., S. and Joshi, D, D, Echinococcus granulosus infections in the dogs of Kathmandu, Nepal. Annuls of Tropical Medicine and Parasitology. 1994; $88,5,485-492$.

5. Schantz P. and B. Gottstein. "Echinococcosis/Hydatidosis" Immunodiagnosis of Parasitic Diseases, Vol. 1, Helminthic Diseases. Ed. Walls and Schantz. Academic press. 1986; 69107.
6. IMD Alexon - Trend, Inc., Ramsey. Echinococcus Serology Screening Test Microwell ELISA Directions for Use for Investigational Use Only, MN. 1997; 55: 303.

7. Joshi D. D. Wald A and Joshi H. Epidemiology of Cystic Echinococcosis/ Hydatidosis Distribution and Transmission Pattern in Kathmandu, Nepal. National Zoonoses and Food Hygiene Research Centre Kathmandu, Nepal. 2000 106-117.

8. Joshi, D D. Unban Echinococcosis in Health Transition Nepal. National Zoonoses and Food Hygiene Research Centre, Kathmandu Nepal. 1999; 13, 21-23, 34-45.

9. Maharjan M. Prevalence of hydatidosis in water buffaloes of western part of Kathmandu. Proceedings of third National Conference on Science Technology, Kathmandu, Nepal. 1999: $587-598$.

10. Paneloza Cabrejos. Ultrasound Classification of hydatid cysts, Archirvos intemationalionales De La Hidatidosis volume xxxii : Lisboa - Portugal. 1997; 225.

11. Ito. A., Liang MA, Peter M. Schantz, Bruno Gottstein, Yue-Han LIU, Jun-Jie Chal, Samik. Abolel - Hafez, Nazmiye Altinatas, Durga D. Joshi, Marshall W. Lightowlers, and Zbigniew Pawlowski S. Differential serodiagnisis for cystic and alveolar Echnicocoosis using flactious of Echinococcus granulosus cyst fluid (Antigen B) and E. multilocularis protoscolex (EM 18) Am. J. Trop. Med. Hyg. 1999; 60 (2), 188-192.

12. Eckert J, and Thompson R.C.A Echinococcus in Europe a review Tropical Medicine and Parasitology, 1988; 39, 1-8.

13. Zhangi, L.H, Joshi, D. D, McManus, D. P and Maharjan, M. Short Report on Genotypes of Echinococcus granulosus Identified in Nepal Using Mitochondrial DNA Markers. Zoonoses and Food Hygiene News. 2000; 6:1, 4.

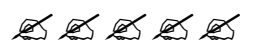

